\title{
Managing a mare for breeding and sport
}

\author{
Dominik Burger ${ }^{2}$, Franziska Wohlfender ${ }^{2}$ and Isabel Imboden' \\ Swiss National Stud, Avenches ${ }^{1}$ and Clinic of Reproduction, University of Zurich, Switzerland
}

\begin{abstract}
Summary
Nowadays in many horse breeds a successful sporting career is required to make a horse eligible for breeding purposes, this may happen before or during its use at stud. For mares, this means careful planning and optimal management of behavioural and reproductive health, especially with the advent of affordable embryo transfer options that allow exploitation of a mare's reproductive potential without a significant break in her career. Unfortunately, there exist as yet only a few research studies in this field. This review article gives a short overview of the actual state of knowledge and the management options for mares, including behavioural management and control of reproductive function through physical, pharmaceutical or immunological means, as well as management of the mare for simultaneous use in breeding and sport.
\end{abstract}

Keywords: sport mare, breeding, oestrous behaviour, GnRH vaccination, embryo transfer, reproduction

\begin{abstract}
Management der Stute für den Einsatz in der Zucht und im Sport
In vielen Zuchten werden heutzutage von den Stuten vorgängig oder gleichzeitig ihres züchterischen Einsatzes immer grössere sportliche Leistungen verlangt. Embryotransfer bietet theoretisch eine Möglichkeit, dass die betroffenen Stuten allen Bedürfnissen gerecht werden können. Die Anforderungen an eine erfolgreiche Zucht- oder Sportstute sind jedoch höchst unterschiedlich. Sind in Wettkämpfen Kraft, Technik, Gesundheit und nicht zuletzt Einstellung und Willen gefragt, so sind es in der Reproduktion die Gesundheit des Genitaltraktes sowie das Geschlechtsverhalten. Deshalb sind ein optimales Management sowie eine sorgfältige Karriereplanung notwendig, wobei aber leider erst wenige wissenschaftliche Studien zu dieser Thematik existieren. In diesem Übersichtsartikel werden die bisherigen Erkenntnisse und zum Teil empirischen - Managementmöglichkeiten von Sportstuten in der Zucht aufgezeigt, inklusive deren Verhaltensmanagement und der Kontrolle der Fortpflanzungsfunktionen durch medikamentelle, mechanische und immunologische Verfahren.
\end{abstract}

Schlüsselwörter: Sportstute, Zucht, Rosseverhalten, GnRH-Vakzination, Embryotransfer, Reproduktion

\section{Introduction}

Nowadays in many horse breeds a successful sporting career is required to make a horse eligible for breeding purposes, this may happen before or during its use at stud. The combination of sporting and reproductive duties is relatively straight forward for stallions, where a supply of frozen semen allows the fulfilment of stud duties whilst the horse is engaged in a sporting career, but presents a much greater challenge for a mare. Another aspect of this problem is that the prerequisites for a horse's success in a breeding or sporting career are somewhat different. In competition power, technique, health and mental attitude decide between success and failure, whereas for breeding the health of the reproductive organs is of crucial importance. For mares, this means careful planning of the sporting career and optimal management of behavioural and reproductive health, especially with the advent of affordable embryo transfer options that allow exploitation of a mare's reproductive potential without a significant break in her career. Unfortunately only relatively few research studies have been done in this field so far. This review article gives a short overview of the actual state of knowledge and the management options for mares, including behavioural management and control of reproductive function through physical, pharmaceutical or immunological means, and management of the mare for simultaneous use in breeding and sport.

\section{Behaviour management of the sport mare}

The suppression of sexual behaviour in mares used for sporting purposes is an issue of considerable importance for both veterinarians and horse owners. Undesirable behavioural traits, especially during oestrus, can make a mare difficult to handle and may have detrimental effects on performance, although the effect of oestrus on athletic performance in the mare is not well understood (Pryor and Tibary 2005). There are numerous methods for targeting this problem, all with advantages and disadvantages. Important factors to consider are reversibility and any lasting detrimental effect on fertility the instigated treatment may have, as any mare currently engaged in a sporting career may be required to breed.

\section{Clinical examination}

If a mare has what an owner considers to be a behavioural problem, a veterinarian is called to carry out a gynaecological examination of the mare so as to check the ovaries for any abnormalities. However, it must be considered that behavioural problems in mares are not always directly associated with oestrus or the reproductive organs in general. Hormonally active ovarian cysts as seen in other species are not known in mares and although in some rare cases ovarian tumours are discovered, in the majority of mares normal cyclic activity is found. It is worth noting that besides behavioural problems, the physiological hormonal fluctuations during the breeding season may be implicated in muscular problems. It is therefore important to record a detailed case history and to perform a thorough orthopaedic examination with particular regard for musculature, the back and stability of the patella.

\section{Covering or castration of the mare}

The most drastic means of suppressing oestrus behaviour are breeding the mare and accepting the ensuing break in the 
mare's sporting career, or terminating the pregnancy after maternal recognition and maintenance of the primary corpus luteum (Lefranc and Allen 2004), which poses ethical problems. Ovariectomy is a further alternative, though not always effective, as some mares can continue to show oestrus signs. This has been attributed to steroids originating from the adrenal cortex (Ginther 1979, Asa et al. 1980, Hooper et al. 1993). Furthermore it carries the disadvantage of surgical risk and permanently eliminating a mare's reproductive potential.

\section{Pharmaceutical treatment}

The most effective means of suppressing oestrus behavioural signs in many mares is to maintain sufficient levels of circulating progesterone. The daily treatment of a mare with gestagens is an efficient method to prevent oestrus and oestrus behaviour by creating an artificial luteal period. Different methods of application include intramuscular administration of exogenous progesterone (50-150 mg in oil) (Roberts and Beaver 1987) or oral administration of the synthetic progestin altrenogest (Regumate ${ }^{\circledR}, 0.044 \mathrm{mg} / \mathrm{kg}$ body weight) (Squires et al. 1993). To attain and maintain oestrus suppression, treatment with Regumate ${ }^{\circledR}$ should be initiated 3 to 4 days prior to a show or event and must be continued daily (McCue 2003). Other progestin products such as medroxyprogesterone acetate, which are mostly labelled for the use in other species, are generally ineffective due to failure to bind adequately to the equine progesterone receptor. There are some points that must be kept in mind when administering gestagen products. With the exception of Regumate ${ }^{\circledR}$, all progesterone-preparations and similar products are classified as non permitted medication in most equestrian federations. Based on a study by Hodgson et al. (2005), where mares receiving altrenogest daily at the recommended dose for 8 weeks did not exhibit any changes in body mass, body condition score or dominance hierarchy compared with untreated control mares, the use of Regumate ${ }^{\circledR}$ is permitted for mares (at the stated dose, not permitted for stallions) with a duty of declaration in international FEl-competitions. With regard to future breeding prospects, another point worth considering is that the long-term treatment with gestagens can augment the uterine susceptibility for inflammation and infection. In addition, their short duration of action, necessitating repeated oral or intramuscular administration, make all progestin products also costly and impractical. As yet, no effective single-dose medications are available to suppress oestrus for a prolonged period of time in mares.

Other methods of reversible suppression of sexual activity are the administration of GnRH antagonists or agonists (Stout and Colenbrander 2004). The antagonist antarelix has been shown to reliably postpone ovulation and increases the interovulatory interval (Watson et al. 2000). The prolonged or high dose administration of $\mathrm{GnRH}$ agonists can result in downregulation of the hypothalomo-pituitary axis, increased inter-ovulatory intervals (Johnson et al. 2002) and in some individuals even in a temporary cessation of ovarian activity (Mumford et al. 1995). All these treatments require frequent administration and generally only result in a short term effect with highly individual responses. Therefore their use for behavioural control is limited.

The field of complementary medicine also offers some pro- mising approaches for controlling oestrus behaviour, for example homoeopathic preparations such as Hyoscyamus niger. McCue (2003) mentions the use of herbal supplements containing Valerian root and Chaste tree berries for calming and modifying undesirable behaviour or altering ovarian function respectively. All these products have never been scientifically tested and the active ingredients may be unknown and not standardised.

\section{Caslick operation}

An unsatisfactory perineal conformation leading to an ineffective vestibular seal can also provoke behavioural problems in mares. Due to incompetent vulval lips (congenital or acquired) and as a result of increase in negative pressure in the pelvic cavity while moving forward, air is sucked in the vagina forming a pneumovagina which can sometimes be heard by the rider while the horse is cantering. This may lead to vaginitis, cervicitis, endometritis and impaired fertility (Troedsson 1997). In those cases a Caslick's vulvoplasty (surgical closure of the dorsal half of the vulva) is indicated for the correction of pneumovagina (Caslick 1937). In a very recent Danish study (Christoffersen et al. 2007) 14 mares exhibiting performance problems such as kicking against the rider's leg, bolting, refusing to move forward, tail swishing and/or symptoms of stiffness in the back were treated with vulvoplastic surgery. In 12 out of the 14 mares (86\%) the performance problems were totally eliminated $(57 \%)$ or diminished (29\%) within 6 months after the procedure. The authors propose that irritating processes in the labia vulvae, vestibulum and vagina of the mare may cause problems attributable to hypersensitivity in dermal areas of the hindquarters. These results confirm a common practice in racing stables, where trainers and veterinarians report better trainability and performance results after Caslick operation in thoroughbred and standardbred mares.

\section{Glass balls}

A procedure which has recently gained in popularity is the manual placement of one to three glass balls of $30-35 \mathrm{~mm}$ in diameter in the uterus, so as to simulate a gestation and induce luteal maintenance. In the only study done on this subject so far, Nie et al. (2001) investigated the effect which an insertion of a $35-\mathrm{mm}$ sterilized glass marble into the uterus within 24 hours of ovulation has on a mare and found prolonged luteal function in 5 of 12 treated mares. Progesterone levels remained elevated in these mares for almost 3 months. In a Swiss field trial involving three clinics and 30 mares, owners reported an amelioration of behaviour in $60 \%$ of treated mares: A total of 12 mares improved significantly, of these, 7 mares showed a long term improvement (>6 months) (Bracher, personal communication 2005). Glass balls are very well tolerated, rarely lost spontaneously and are easily removed by manual manipulation per rectum.

\section{Immunization against $\mathrm{GnRH}$}

The manipulation of the reproductive activity through the use of a $\mathrm{GnRH}$ vaccination was first developed for farm animals as 
this method offers an alternative to surgical castration for minimizing sexual and aggressive behaviour, suppressing reproductive function and preventing pregnancy (Esbenshade and Britt 1985). Several studies investigating the effect of $\mathrm{GnRH}$ vaccination have been carried out on mares, some documenting effective suppression of ovarian function and oestrous behaviour along with a subsequent reversal of these effects (Tshewang et al. 1997), while others documented greater individual variation and a less reliable result (Dalin et al. 2002).

In a study by Imboden et al. (2006) the effect of vaccination on reproductive cyclicity, plasma progesterone and estradiol$17 \beta$ concentration and antibody titres was investigated using 18 mature cyclic mares randomly divided into a treatment and control group. The study included weekly ultrasonic examination of uterus and ovaries and simultaneous documentation of oestrous behaviour. Results demonstrate that vaccination against $\mathrm{GnRH}$ significantly ( $\mathrm{P}<0.05$ ) influenced all parameters, except estradiol-17 $\beta$ concentration. All vaccinated mares ceased reproductive cyclicity within 8 weeks after the first injection, and ovarian activity remained suppressed for a minimum of 23 weeks. Five mares returned to normal reproductive cyclicity, but three mares showed only follicular activity and one mare remained completely suppressed for the entire duration of 60 months of the study. This study therefore concludes that vaccination of mares with Improvac ${ }^{\circledR}$ (Pfizer Animal Health, Australia) is an extremely effective method of suppressing reproductive function, but leads to highly variable responses in the mares, and that reversal can not be guaranteed. A persistent anoestrous state has also been anecdotally reported by Australian practitioners after multiple vaccinations of young thoroughbred mares. Furthermore, the study also mentions that some mares continued showing sporadic bouts of oestrous behaviour, independent of ovarian function. This phenomenon probably has a similar origin as the oestrous behaviour noted in ovariectomised mares (see above).

Until recently, there was no vaccine available that was produced for use in equines; this led to considerable adverse reactions including painful swelling and stiffness at the site of injection and a febrile period lasting several days. A new commercially available vaccine (Equity ${ }^{\top M}$, Pfizer Animal Health, Australia), with a modified adjuvant and carrier protein has been designed specifically for use in the horse. A recent study from Australia (Elhay et al. 2007) documents the effect of this vaccine on 24 mares (12 treated, 12 control) using a conventional two-dose immunization regime: All mares responded to vaccination with Equity ${ }^{\top M}$ with an effect that lasted for a minimum of 3 months and correlated with the initial level of antibody response. This vaccine has a high level of safety since there were no significant local reactions nor were there any adverse systemic responses to vaccination. This vaccine would therefore appear to be a safe and effective method of suppressing sexual function in mares, although some doubt remains about its long term effect on a mares reproductive potential after repeated use.

\section{Breeding management of the sport mare}

At a certain stage in a mare's sporting career, the question of breeding from her arises for many owners. If so, the owner must decide whether to wait until she finishes her competitive career, with the risk that she might have few reproductively useful years left, whether to use an injury imposed break or whether to utilise her genetic potential in-between competitions in an embryo transfer program (Stout 2003).

Covering, early pregnancy and concurrent use of the mare in the sport

The covering of mares which come directly from sport or which serve as embryo donors and are therefore only on a very short break from full training is often problematic. In theory, embryo transfer offers a great benefit to sport-horse breeding. However the demands of synchronisation, covering and embryo recovery can lead to training problems and in the opinion of a lot of riders to a drop in performance. The stress of high intensity training or competition may also have a negative effect on cyclicity and fertility (Stout 2003). Unfortunately only very few studies exist addressing this issue. Using 16 mares, Mortensen et al. (2006) found that the embryo recovery rate from exercised mares was only about half of that of non-exercised mares. In addition, a significantly greater proportion of embryos collected from exercised mares were morphologically damaged. According to the authors, effects of thermal stress or direct effects of exercise could be responsible for that. To the authors knowledge this is the only case controlled study in existence. These results are supported by observations from the field by Koene (1990) and by Allen and Stout (1999) where relatively low recovery and transfer rate in performance mares and accordingly low final live birth rates were observed. Stress has been proposed by Osborne (1975) in slaughter horse mares and by Mitchell and Allen (1975) in mares first bred as yearlings as an import factor for embryonic death. Van Niekerk and Morgenthal (1982) observed a decline in total peripheral progesterone levels in pregnant mares which experienced stress due to pain and infectious disease. He presumed this to be due to corticoid release. In a study on intensity of stress reaction in the mare during transportation at different stages of ovarian activity and pregnancy, Tischner et al. (2006) found the most intensive stress reactions in mares in dioestrus and during the winter anoestrus. The longest stress reaction was recorded during foal heat and early pregnancy respectively. In contrast, a reduction of stress response was observed in late pregnancy indicating that at this point there are some mechanisms protecting the foetus against stressful influences.

It therefore seems to be advisable that during covering, whether through natural mating or artificial insemination, stress for the mare is minimized. Sources of stress for a mare include factors such as changes in her environment or in her working schedule. During the time of covering, mares should be exercised normally but hard work, long transports and competing should be avoided. An empirical rule of experienced breeders says that mares should be rested up to six weeks after covering.

These facts have to be considered also for mares in embryo transfer programs. It is recommended to devote a defined period of time solely to embryo recovery, as it is done during the non-competition season for polo ponies in Argentina (Stout 2003). For warmblood horses this period could be early spring before the beginning of the competition season. Allen and Stout (1999) propose that the donor mares should 
be temporarily resident at well organised equine reproduction facilities around the time of insemination and ovulation.

\section{Competition and performance during pregnancy}

After the "covering-break" a return to competing may be considered. The individual's performance level and the nature of the sporting discipline in which the mare is engaged have to be taken into account. In many cases it is possible for mares in early pregnancy to take part in show jumping and dressage competitions. In some equestrian disciplines specific rules exist concerning pregnant mares in the sport - no pregnant mares are allowed in any endurance competition and no mares which are over four months pregnant are permitted in trotting races. There are no concrete rules for eventing or flat racing, but competing is considered to be irresponsible from quite an early stage of gestation.

From the fifth month of gestation on, the uterus and foetus start to sink into the abdominal cavity. Depending on the condition of the abdominal musculature, a mare's girth may increase between the seventh and ninth month of gestation. The growing embryo also compromises the mare's breathing through pressure on the diaphragm. Training and competing at this stage are no longer feasible. Nevertheless quiet hakking may be possible until shortly before foaling as long as the mare is motivated.

\section{Back to sport after foaling?}

When planning a mare's foaling break, it must be considered that the foal can not be weaned before fourth months at the earliest. During this time intensive training and competing are almost impossible. Frequent separation of mare and foal can lead to severe stress, restlessness or even accidents. After weaning, the rebuilding and retraining of the muscles, especially those of the abdomen and back, and the adaptation of the older mare's metabolism and her motivation to work can be time consuming and difficult to manage.

\section{References}

Allen W. R. and Stout T. A. E. (1999) A failed attempt to collect, transport and transfer embryos from competing mares. Proceedings of the first meeting of the European Equine Gamete Group, Lopuszna, Poland, Havemeyer Foundation Monograph Series, 63-65

Asa C. S., Goldfoot D. A., Garcia M. C. and Ginther O. J. (1980) Sexual behaviour in ovariectomized and seasonally anovulatory pony mares (Equus caballus). Horm. Behav. 14, 46-54

Caslick E. A. (1937) The vulva and the vulvo-vaginal orifice and its relation to genital health of the thoroughbred mare. Cornell Vet. 27, 178-187

Christoffersen M., Lehn-Jensen H. and Bogh I. (2007) Referred vaginal pain: Cause of hypersensitivity and performance problems in mares? A clinical case study. J Equine Vet. Sci. 27, 32-36

Dalin A. M., Andresen O. and Malmgren L. (2002) Immunization against $\mathrm{GnRH}$ in mature mares: antibody titres, ovarian function, hormonal levels and estrous behavior. J. Vet. Med. 49, 125-131

Elhay M., Newbold A., Britton A., Turley P., Dowsett K. and Walker J. (2007) Suppression of behavioural and physiological oestrus in the mare by vaccination against $\mathrm{GnRH}$. Aust. Vet. J. 85, 39-45

Esbenshade K. L. and Britt J. H. (1985) Active immunization of gilts against gonadotropin-releasing hormone-effects on secretion of gonadotropins, reproductive function, and responses to agonists of gonadotropin-releasing hormone. Biol. Reprod. 33, 569-577
Ginther O. J. (1979) Sexual behaviour. In: Reproductive biology of the mare, basic and applied aspects. First edition, Equiservices, Wisconsin, 59-82

Hodgson D., Howe S. and Jeffcott L. (2005) Effect of prolonged use of altrenogest on behaviour in mares. Vet. J. 169, 113-115

Hooper R. N., Taylor T. S., Varner D. D. and Blanchard T. L. (1993) Effects of bilateral ovariectomy via colpotomy in mares: 23 cases (1984-1990). J. Am. Vet. Med. Assoc. 203, 1043-1046

Imboden I., Janett F., Burger D., Crowe M. A., Hässig M. and Thun $R$. (2006) Influence of immunization against $\mathrm{GnRH}$ on reproductive cyclicity and estrous behavior in the mare. Theriogenology 66, 1866-1875

Johnson C. A., Thompson D. L. and Cartmill J. A. (2002) Pituitary responsiveness to $\mathrm{GnRH}$ in mares following deslorelin acetate implantation to hasten ovulation. J. Anim. Sci. 80, 2681-2687

Koene M. (1990) Untersuchungen zur Superovulation der Stute mittels HMG-Stimulation im Rahmen eines Embryotransferprogrammes. Med. Vet. Diss. Hannover

Lefranc A. C. and Allen W. R. (2004) Nonpharmacological suppression of oestrus in the mare. Equine Vet. J. 36, 183-185

McCue P. (2003) Estrus suppression in performance horses. J. Equine Vet. Sci., 23, 342-344

Mitchell D. and Allen W. R. (1975): Observations on reproductive performance in the yearling mare. J. Reprod. Fertil. Suppl. 23, $531-536$

Mortensen C., Choi Y. H., Hinrichs K., Ing N., Kraemer D., Vogelsang S. and Vogelsang M. (2006) Effects of exercise on embryo recovery rates and embryo quality in the horse, Anim. Reprod. Sci. 94, 395-397

Mumford E. L., Squires E. L., Jochle E., Harrison L. A., Nett T. M. and Trigg T. E. (1995) Use of deslorelin short-term implants to induce ovulation in cycling mares during 3 consecutive estrous cycles. Anim. Reprod. Sci. 39, 129-140

Nie G. J., Johnson K. E., Braden T. D. and Wenzel J. G. W. (2001) Use of a glass ball to suppress behavioral estrus in mares. Proc. Am. Assoc. Equine Pract. 47, 246-248

Osborne V. E. (1975) Factors influencing foaling percentages in Australian mares. J. Reprod. Fertil. Suppl. 23, 477-483

Pryor P. and Tibary A. (2005) Management of estrus in the performance mare. Clin. Tech. Equine Pract. 4, 197-209

Roberts S. J. and Beaver B. V. (1987) The use of progestagen for aggressive and hypersexual horses. In: Current therapy in equine medicine 2, Robinson N. E., ed. Philadelphia: WB Saunders, 129-131

Squires E. L. (1993) Progestin. In: Equine Reproduction, McKinnon A. O., Voss J. L., eds. Philadelphia, London: Lea and Febinger, 31 1-318

Stout T. A. E. (2003) Selection and management of the embryo transfer donor mare. Pferdeheilkunde 19, 685-688

Stout T. A. E. and Colenbrander B. (2004) Suppressing reproductive activity in horses using $\mathrm{GnRH}$ vaccines, antagonists or agonists. Anim. Reprod. Sci. 82-83, 633-643

Tischner M., Niezgoda J. and Tischner M. (2006) Intensity of stress reaction in the mare during transportation at different stages of ovarian activity and pregnancy. Anim. Reprod. Sci. 94, 234-237

Troedsson M. H. T. (1997) Diseases of the external genitalia. In: Current therapy in equine medicine -4 , Robinson N. E., ed. Philadelphia: WB Saunders, 512-516

Tshewang U., Dowsett K. F., Knott L. M. and Trigg T. E. (1997) Preliminary study of ovarian activity in fillies treated with a GnRH vaccine. Aust. Vet. J. 75, 663-667

Van Niekerk C. H. and Morgenthal J. C. (1982) Fetal loss and the effect of stress on plasma progesterone levels in pregnant Thorougbred mares. J. Reprod. Fertil. Suppl. 32, 453-457

Watson E. D., Pedersen H. G., Thomson S. R. and Fraser H. M. (2000) Control of follicular development and luteal function in the mare: effects of a GnRH antagonist. Theriogenology 54, 599-609

Dominik Burger

University of Zurich

8057 Zürich

Switzerland

dominique.burger@harasnational.ch 